\title{
Proteção financeira dos idosos à luz da lei geral de proteção de dados
}

\author{
Financial protection of the elderly in light of the general data protection law \\ Protección financiera de las personas mayores a la luz de la ley general de protección de datos
}

Recebido: 23/09/2021 | Revisado: 28/09/2021 | Aceito: 29/09/2021 | Publicado: 01/10/2021

\author{
Deise Mara Soares Bonini \\ ORCID: https://orcid.org/0000-0002-7425-6880 \\ Autônomo, Brasil \\ E-mail: deisemarasoares98@gmail.com \\ Fernanda Correa de Melo \\ ORCID: https://orcid.org/0000-0002-4091-4486 \\ Autônomo, Brasil \\ E-mail: fernandacorreademelo@gmail.com \\ Murilo Bastos \\ ORCID: https://orcid.org/0000-0003-0358-8738 \\ Universidade Estadual do Centro-Oeste, Brasil \\ E-mail: murilo_bastos@yahoo.com.br \\ Weber Cláudio Francisco Nunes da Silva \\ ORCID: https://orcid.org/0000-0002-4688-3115 \\ Universidade Estadual do Centro-Oeste, Brasil \\ E-mail:wwwclaudion@gmail.com \\ Juliana Sartori Bonini \\ ORCID: https://orcid.org/0000-0001-5144-2253 \\ Universidade Estadual do Centro-Oeste, Brasil \\ E-mail: jbonini@unicentro.br
}

\begin{abstract}
Resumo
A presente pesquisa investiga a proteção legal da população idosa frente aos avanços tecnológicos e, consequentemente, aos crimes cometidos no ciberespaço. O objetivo da pesquisa é analisar se a recente Lei Geral de Proteção de Dados resguarda, substancialmente, os idosos, visto que são as vítimas preferenciais dos cibercriminosos, os quais se utilizam de habilidosas engenharias sociais para perpetrar fraudes financeiras. A pesquisa foi realizada através de revisão bibliográfica, de caráter exploratório junto à doutrina, notícias jornalísticas e dados estatísticos. O estudo foi realizado por meio de análise de conteúdo, na modalidade temática, seguindo as etapas de pré-análise, com organização do material coletado; exploração do material; tratamento e interpretação dos resultados com a realização da síntese interpretativa, interligando os artigos científicos e as informações documentais. Ao final, pôde-se concluir que a lei analisada resguarda os direitos à intimidade, privacidade e dignidade, especialmente da população idosa, na medida em que protege os dados pessoais de todos os indivíduos, dificultando, assim, o uso indiscriminado destas informações.
\end{abstract}

Palavras-chave: Idosos; Cibercrimes; Proteção; Dados pessoais.

\begin{abstract}
This research investigates the legal protection of the elderly population against technological advances and, consequently, crimes committed in cyberspace. The objective of the research is to analyze whether the recent General Data Protection Law (LGPD) substantially protects the elderly, as they are the preferred victims of cybercriminals, who use skillful social engineering to perpetrate financial fraud. The research was carried out through a bibliographical review, of an exploratory character with the doctrine, journalistic news and statistical data. The study was carried out through content analysis, in the thematic modality, following the pre-analysis steps, with organization of the collected material; exploration of the material; treatment and interpretation of results with the performance of the interpretative synthesis, linking scientific articles and documentary information. In the end, it could be concluded that the LGPD protects the rights to intimacy, privacy and dignity, especially of the elderly population, as it protects the personal data of all individuals, thus hindering the indiscriminate use of this information.
\end{abstract}

Keywords: Elderly; Cybercriminals; Protection; Personal data.

\section{Resumen}

Este análisis investiga la protección legal de la población anciana frente a los avances tecnológicos y, en consecuencia, los delitos cometidos en el ciberespacio. El objetivo de la investigación es analizar si la reciente Ley General de Protección de Datos protege sustancialmente a las personas mayores, ya que son las víctimas preferidas de los ciberdelincuentes, que utilizan hábil ingeniería social para perpetrar fraudes financieros. La investigación se realizó mediante de una revisión bibliográfica, de carácter exploratorio, junto con la doctrina, la actualidad 
periodística y los datos estadísticos. El estudio se realizó mediante análisis de contenido, en la modalidad temática, siguiendo los pasos de preanálisis, con organización del material recolectado; exploración del material; tratamiento e interpretación de resultados con la realización de la síntesis interpretativa, vinculando artículos científicos e información documental. Al final, se pudo concluir que la ley analizada protege los derechos a la intimidad, privacidad y dignidad, especialmente de la población anciana, ya que protege los datos personales de todas las personas, dificultando así el uso indiscriminado de esta información.

Palabras clave: Anciano; Crímenes cibernéticos; Proteccion; Datos personales.

\section{Introdução}

Envelhecer é parte do desenvolvimento humano e acontece de forma heterogênea, sendo influenciado por fatores econômicos, políticos, sociais e genéticos. Por se tratar de um processo de perdas e maior exposição a doenças, o envelhecimento pode trazer vulnerabilidades sociais, emocionais e físicas, como a dependência e a predisposição a situações de violência (Irigaray et al., 2016). Assim, são inúmeras as reflexões existentes acerca do crescente aumento da população idosa e as consequências (Guimarães et al., 2016).

Entre as preocupações com a pessoa idosa, estão as várias formas de violência, caracterizadas por abandono, negligências, abusos psicológicos, físicos, financeiros, provocados por cuidadores e/ou familiares e em instituições de longa permanência (WHO, 2002).

A forma de violência praticada e a gravidade desta estão relacionadas à vulnerabilidade do idoso. Apesar da saúde pública atender as principais demandas dentro da temática, este não é um desígnio específico da área da saúde, visto que uma atenção multiprofissional é necessária (Lima, 2014). A violência contra o idoso sempre esteve presente na sociedade, existindo carência de políticas públicas e despreparo para debater e tomar providências sobre o assunto (Reis et al., 2014).

Diante das diversas formas de violência, o foco deste trabalho é a violência financeira, que tem merecido atenção pela sua alta ocorrência. Ela se caracteriza por saques de dinheiro com cartão e senha, roubos de bens/imóveis, privação do idoso aos próprios pertences, entre outros. Tal violência acontece quando os familiares ou responsáveis do idoso fazem apropriação indevida dos recursos deste, comprometendo a renda mensal sem autorização, manipulando, ameaçando ou coagindo o idoso (Moreira et al., 2016).

$\mathrm{O}$ abuso financeiro ocorre mais frequentemente quando a pessoa idosa possui algum tipo de comprometimento cognitivo ou funcional, não conseguindo cuidar das finanças pessoais e precisando delegar a função. A dependência financeira do agressor em relação ao idoso pode configurar um fator de risco para outras formas de violência (Silva et al., 2016).

No estado do Paraná, no ano de 2020, houve um aumento de $83 \%$ nos casos de denúncia em relação ao ano anterior através do Disque Idoso. No ranking das violações tipificadas, em primeiro lugar ficou a violência financeira e patrimonial, seguida por negligência. Os dados revelaram que geralmente a pessoa idosa em situação de violência sofre mais de uma violação de direitos, sendo enquadrado em uma mesma denúncia três ou quatro tipos, de acordo com o Estatuto do Idoso (2020).

É fundamental que profissionais de diferentes áreas, atuantes na Rede de Proteção e Atendimento a Pessoa Idosa, estejam atentos e preparados para reconhecer atos de violência, a fim de promover e garantir os direitos da pessoa idosa. Uma sociedade que busca uma vida mais justa é aquela que desenvolve a cultura de valorização, reconhecendo que o envelhecimento é uma conquista humana. Viver é um direito que deve ser exercido com respeito e dignidade (2020).

Em atenção a questão da violência financeira e patrimonial contra o idoso, a legislação brasileira tem buscado se adequar e agir de forma preventiva. Como por exemplo a Recomendação 46 do Conselho Nacional de Justiça (CNJ), que trouxe orientações direcionadas a cartórios, para tentar reduzir práticas abusivas contra pessoas idosas, como antecipação de herança, venda de imóveis, movimentação indevida de conta bancária, tomada ilegal e mau uso de fundos, bens ou ativos, uso ilegal de recursos sem consentimento (Verdi, 2021). 
Na mesma direção está a Lei Geral de Proteção de Dados (LGPD) ou lei n n 13.709, aprovada em 2018 e com vigência a partir de agosto de 2020. O objetivo desta lei é proporcionar um cenário de segurança jurídica, padronizando normas e práticas e promovendo de forma igualitária a proteção aos dados pessoais de todo cidadão brasileiro (Lei, 2018). Em relação ao idoso e a proteção de dados, a referida lei "garante que o tratamento de dados de idosos seja efetuado de maneira simples, clara, acessível e adequada ao seu entendimento, nos termos da Lei $n^{\circ} 10.741$, de $1^{\circ}$ de outubro de 2003 (Estatuto do Idoso)" (Leite, 2021).

Considerando o contexto e a relevância da proteção de dados e a população idosa, este estudo objetivou realizar uma análise da proteção financeira dos idosos à luz da Lei Geral de Proteção de Dados, tendo como base a literatura disponível sobre a temática, a fim de gerar um debate sobre o impacto da LGPD no cuidado e proteção para com a pessoa idosa.

Passa-se, agora, ao levantamento bibliográfico sobre a temática deste estudo. Primeiro será descrito um breve histórico da proteção de dados no ordenamento jurídico brasileiro; depois será trazido os princípios da Lei de Proteção de Dados; na sequência será mencionada a vulnerabilidade da população idosa frente aos avanços tecnológicos da era digital e, por fim, será trazido a importância da proteção financeira de idosos.

\subsection{Histórico da proteção de dados no ordenamento jurídico brasileiro}

A divulgação em massa de dados na internet, chamada de "datificação das coisas", faz com que o titular das informações tenha seus direitos violados. Essa situação gera a necessidade de proteger os dados e do titular ter controle sobre elas, pois cada vez mais informações transitam pela internet em velocidade e número exponenciais (Lugati et al., 2020).

Ao considerar que a vida online e offline do usuário se misturam nas redes, as violações a diversos direitos fundamentais e a constante violação da privacidade ficam mais constantes. Diante disso, é importante que exista uma legislação acerca da proteção de dados que aborde integralmente o direito à proteção de dados, colocando o titular como sujeito ativo no processamento de dados, devendo ter ciência do que acontece, visto que está em uma situação de vulnerabilidade (Bioni, 2020).

De forma indireta, a proteção de dados já estava presente na legislação brasileira, como na Lei do Cadastro Positivo (Lei no 12.414/2011), no Marco Civil da Internet (Lei 12.965/2014) e no Código de Defesa do Consumidor (Lei 8.078/1990). Apesar disto, ainda não existia uma regulamentação específica sobre a proteção de dados. Na linha do tempo, outros países implementaram suas leis antes do Brasil, como os países da União Europeia, que tem no seu histórico a Diretiva 95/46 e a Convenção 108, implementando uma legislação mais extensiva para proteção de dados e regulamentando o tratamento de dados. Foi a partir deste exemplo que a proteção de dados ganhou visibilidade em outros países. Já no Brasil, a Lei Geral de Proteção de Dados (LGPD) foi criada somente no ano de 2018 (Lugati et al., 2020).

Historicamente, no Brasil, a primeira movimentação a fim de criar uma lei para proteção de dados foi a atual Constituição Federal (1988), que mencionou, em seu artigo 5º o tema privacidade dos brasileiros: "são invioláveis a intimidade, a honra, a vida privada e a imagem das pessoas, assegurando o direito a indenização pelo dano material ou moral decorrente da violação" (Assis el al., 2021).

No sentido da CF/88, a proteção de dados está compreendida como um direito de personalidade; um direito do indivíduo poder escolher e determinar suas informações pessoais e como serão compartilhadas, sendo assim, um Direito Fundamental (Mendes, 2014). Partindo disto, sempre houve a urgência de implantar uma legislação mais específica, respeitando os direitos considerados fundamentais e previstos na $\mathrm{CF} / 88$, tais como a privacidade e inviolabilidade de dados pessoais (Stelzer et al., 2019).

Em 1993, o próximo passo do Brasil rumo a desenvolver uma legislação para proteção de dados foi o Código de Defesa do Consumidor, um manual elaborado para especificar as relações entre empresas e clientes. Neste documento, há uma 
seção sobre os cadastros e banco de dados, onde é defendido o direito do consumidor em acessar dados que determinada empresa tem sobre ele, solicitando sua correção quando necessário (Assis el al., 2021).

Ainda sobre o Código de Defesa do Consumidor, no artigo 13, fica claro que se uma empresa dificultar que o sujeito acesse as próprias informações ou deixe de comunicar ao titular o registro dos dados é considerado uma infração. Ademais, em seu artigo 11, capítulo III, está garantida a privacidade, responsabilizando empresas sobre a segurança de dados: “...dados pessoais do consumidor deverão ser preservados, mantidos em sigilo e usados para fins de atendimento, exclusivamente" (Assis el al., 2021).

No ano de 1996, a Lei $\mathrm{n}^{\circ}$ 9.296/96, que regulamentou o artigo $5^{\circ}$ da $\mathrm{CF} / 88$, acrescentou o seguinte: "o sigilo da correspondência e de comunicações telefônicas é inviolável, salvo se, por ordem judicial, na forma e na hipótese em que a lei estabelecer, a fim de investigação criminal ou instrução processual penal” (Mendes, 2014).

Cabe mencionar que quando a União Europeia promulgou, no ano de 1995, a Diretiva Europeia de Proteção de Dados Pessoais e colocou os membros do bloco econômico sob a mesma legislação - Parlamento Europeu e Conselho Europeu - até a substituição no ano de 2018 pelo Regulamento Geral sobre a Proteção de Dados (GDPR), muitos países se influenciaram a rever suas legislações, incluindo o Brasil. Tal ato da União Europeia influenciou diretamente o Brasil a aprovar uma legislação específica anos mais tarde (Rodotà, 2008).

Dando continuidade, em 2013 uma outra referência importante para a privacidade no Brasil foi o "Marco Civil da Internet", primeira lei responsável por regular a utilização da internet no país, servindo como pontapé inicial para que a justiça brasileira começasse a entender os efeitos do uso da internet. Entre os conceitos introduzidos com o referido documento estão a neutralidade da rede e a liberdade de expressão, além de definições sobre as obrigações dos órgãos públicos no fornecimento da rede de internet (Assis el al., 2021).

Ainda em 2013, o decreto $n^{\circ} 7.962$ trouxe algumas orientações a fim de complementar o Código de Defesa do Consumidor, definindo as diretrizes para o Plano Nacional de Consumo e Cidadania, declarando em seu artigo $2^{\circ}$ : "privacidade, confidencialidade, autodeterminação e segurança de dados pessoais e informações prestadas ou coletadas, inclusive por meio eletrônico" (Assis el al., 2021).

Seguindo, em 14 de agosto de 2018, foi aprovada a Lei n 13.709, chamada de Lei Geral de Proteção de Dados Pessoais (LGPD), que configurou um importante marco legislativo brasileiro ao alterar de maneira significativa a coleta e tratamento dos dados pessoais. Tal lei entrou em vigor em 18 de setembro de 2020 e traz fundamentos que afirmam a proteção de garantias e direitos da pessoa, tais como respeito a liberdade de expressão, privacidade, não violação da intimidade, desenvolvimento tecnológico e econômico, livre iniciativa e respeito aos direitos humanos, entre outros (Maldonado et al., 2019).

No último dia 19 de janeiro de 2021, pesquisadores do dfndr lab, laboratório de segurança da Psafe (Pecsen, 2021), identificaram um vazamento de dados em massa do CPF de mais de 220 milhões de brasileiros. Emilio Simoni, diretor do dfndr lab, explica:

O mais comum é que os dados sejam utilizados para golpes de phishing, uma vez que o cibercriminoso tenha o CPF e outros dados reais da pessoa, seria fácil se passar por um serviço legítimo e utilizar engenharia social para obter dados mais críticos da vítima, que poderiam ser utilizados para pedir empréstimos, senha de banco e contratações de serviços, por exemplo (Pecsen, 2021). 
Normalmente os dados pessoais furtados são vendidos na deep $w_{e} b^{l}$ e, na era digital de atendimentos automatizados e remotos, são utilizados para compras e vendas de bens, contração de dívidas, saques indevidos de FGTS, pedidos de auxílio emergencial, bem como benefícios previdenciários.

O cibercrime acima relatado está sendo apurado pela Autoridade Nacional de Proteção de Dados - ANPD, a qual está buscando as fontes do vazamento e analisando sobre a aplicação de multas. Ressalta-se que, de fato, somente a partir de agosto de 2021 as penalidades para este tipo de vazamento poderão ser aplicadas, variando entre sanções administrativas e altas multas.

Assim, verifica-se que a criação da LGPD é um marco na proteção dos direitos fundamentais dos indivíduos. Dentre as diversas disposições que a premencionada lei trouxe, os princípios que deverão ser respeitados por ocasião do tratamento de dados das pessoas naturais e a definição de alguns termos primordiais para compreensão do tema, merecem uma análise mais aprofundada.

\subsection{Princípios informadores da lei geral de proteção de dados}

No sentido de disciplinar a coleta e o tratamento de dados pessoais através de uma legislação específica sobre o tema, o Brasil buscou se adequar e formular a Lei $\mathrm{n}^{\circ}$ 13.709/2018, já mencionada acima, conhecida como LGPD, a qual busca garantir os direitos ao cidadão, oferecendo fundamentos para o desenvolvimento econômico a partir do uso da informação e dados pessoais (Mendes et al., 2018).

Sofrendo a influência de outros sistemas jurídicos, como as normas do modelo europeu para proteção de dados, especialmente o Regulamento Geral de Proteção de Dados (Regulamento 649/2016) e a Convenção 108 do Conselho Europeu, de 1981 (Mendes et al., 2018), assim como inspiração em leis brasileiras, a LGPD foi regulamentada em 2018.

Em vigor desde 16 de agosto de 2020, a LGPD abrange qualquer atividade de tratamento de dados pessoais, proveniente de pessoa física ou jurídica, direito público ou privado, meio físico ou eletrônico, visando ou não o fornecimento de bens e serviços, desde que aconteça em território nacional (BRASIL, 2018). Destaca-se que desde 2010 a LGPD estava sendo desenvolvida, inserindo o Brasil entre os países com legislações completas sobre proteção de dados, seguindo a mesma linha de legislações mais atuais, como a GDPR (Stelzer et al., 2019).

A LGPD menciona o tratamento de dados pessoais, resguardando os direitos fundamentais de privacidade, intimidade e liberdade dos cidadãos a fim de protegê-los, não abrangendo os dados das pessoas jurídicas, patentes e softwares, informações sigilosas, por exemplo, pois estas já são tuteladas por outras leis do ordenamento jurídico, como a Lei de Software (9.609/1998) e Lei de Propriedade Industrial (9.610/1998) (Stelzer et al., 2019).

Antes de entrar no quesito "princípios da LGPD", é importante compreender alguns conceitos de que trata a referida lei, a fim de assimilar e compreender melhor o que é tratado, tais como: dados pessoais; dados pessoais sensíveis; dados anonimizados; processamento/tratamento de dados (Gomes, 2019).

Os dados pessoais são informações sobre uma pessoa que pode ser identificada, seja por localização, identificação, genética, etc. Enquanto dados pessoais sensíveis fazem referência à etnia, raça, religião, filiação a sindicatos, filosofia seguida, posicionamento político, saúde, vida sexual, dado biométrico, etc. Mentiras ou informações incorretas sobre uma pessoa também se encaixam em dados pessoais, sendo irrelevante o meio em que é divulgada a informação (texto, vídeo, foto, áudio) (Paludetto et al., 2019).

\footnotetext{
${ }^{1}$ Em livre tradução é a internet profunda; trata-se de uma área escondida da internet, com transações anônimas e, geralmente, criminosas.
} 
Os dados anonimizados compreendem dados pessoais que podem deixar de ser protegidos por lei caso seja anonimizado, a partir da "utilização de meios técnicos no momento do tratamento, onde se perde associação direta ou indireta com o sujeito" (Lei, 2018, Art. $5^{\circ}$ ).

Por fim, o tratamento ou processamento de dados é uma definição mais abrangente que envolve toda a LGPD. Processar um dado significa qualquer ação que seja realizada em dados pessoais, através de meios automatizados ou não, a saber: consulta, recuperação, alteração, adaptação, armazenamento, organização, registro, coleta, estruturação, divulgação, alinhamento, combinação, restrição, destruição. Por isso, qualquer ação que envolva dados de terceiros se encaixa na LGPD (2018).

Dando continuidade, ao pré-citada lei, Gomes (2019) afirma que esta lei traz princípios em que precisam estar baseados todo e qualquer tratamento de dados, sendo eles: princípio da finalidade; princípio da adequação; princípio da necessidade; princípio do livre acesso; princípio da qualidade dos dados; princípio da transparência; princípio da segurança; princípio da prevenção; princípio da não discriminação; princípio da responsabilização e prestação de contas.

Todos estes princípios estão referenciados na LGPD e serão descritos resumidamente a seguir (2018).

A) Princípio da finalidade: envolve o tratamento de dados para propósitos legítimos, explícitos, específicos e informados ao titular, sem possível tratamento posterior que não seja para estes fins. Desta forma, qualquer coleta e/ou processamento de dados deve ser explicado de maneira clara ao titular, que deve estar de acordo com o procedimento e delimitações do uso de dados. Acrescenta-se que este domínio só poderá sofrer tratamento diverso do previamente informado se houver nova, expressa e específica concordância do titular.

B) Princípio da adequação: os dados coletados devem ter uma pertinência lógica em relação ao tratamento destes dados e a finalidade objetivada, não fugindo ao que foi informado ao titular dos dados.

C) Princípio da necessidade: apregoa um tratamento e coleta de dados mínimo para atender determinada finalidade. Desta forma, não é permitido que sejam coletados dados em excesso do titular, dados que não sejam necessários para atingimento do objetivo da coleta.

D) Princípio do livre acesso: garante que os titulares possam consultar seus dados de forma gratuita e facilitada, por quanto tempo quiserem, independente da finalidade, garantindo, ainda, a integralidade destes dados. Acrescenta-se que, antes do tratamento dos dados, o titular deve ser cientificado, gratuitamente, da forma que poderá acessar seus dados já tratados.

E) Princípio da qualidade dos dados: preconiza a exatidão dos dados, ou seja, no ato da coleta os dados precisam ter clareza e relevância ao serem solicitados ao titular. Ademais, alguns dados coletados podem ser dinâmicos, impondo-se, assim, sua constante atualização.

F) Princípio da transparência: as informações devem estar disponíveis para o acesso ao titular, de maneira precisa e clara, bem como sobre os agentes de tratamento; sempre em linguagem compreensível ao cidadão de qualquer grau de cultura.

G) Princípio da segurança: refere que os dados coletados sejam armazenados de forma segura, a fim de não serem acessados de maneira indevida. Assim, os agentes de coleta e tratamento devem adotar medidas de segurança eficazes para a proteção dos dados, não importando, para a responsabilização civil, se a violação se deu por ato ilícito ou acidental. 
H) Princípio da prevenção: envolve a adoção de medidas para prevenir danos ao titular dos dados coletados e tratados. Na verdade, o presente princípio apenas reitera o da segurança, retro definido.

I) Princípio da não discriminação: defende que o tratamento de dados pessoais deve ser impedido se a finalidade for discriminação, atos ilícitos ou abusivos. Inclui-se, neste princípio, a vedação à utilização excessiva dos dados pessoais, derrubando o nexo lógico com a finalidade.

J) Princípio da responsabilização e prestação de contas: determina que as empresas devem prestar contas sobre a adoção de medidas que garantam o cumprimento de normas que protejam os dados pessoais, comprovando a eficácia destas medidas. Assim, não basta o agente de tratamento demonstrar a adoção de medidas protetivas aos dados pessoais, deverá comprovar que estas medidas foram eficazes.

\subsection{Vulnerabilidade da população idosa frente aos avanços tecnológicos}

É um fato: somos uma sociedade de idosos. E isso graças à qualidade de vida que adquirimos ao longo dos anos, especialmente em razão dos avanços científicos e tecnológicos. De acordo com a Organização Mundial da Saúde - OMS (2005, p. 8), "o envelhecimento da população é um dos maiores triunfos da humanidade". Ainda, sobre esta conquista, lecionam Veras e Caldas (2004, p. 424):

O século XX se caracterizou por profundas e radicais transformações, destacando-se o aumento do tempo de vida da população como o fato mais significativo no âmbito da saúde pública mundial. Uma das maiores conquistas da humanidade foi à extensão do tempo de vida.

A Organização das Nações Unidas - ONU demonstrou, pela primeira vez, em 1982, no Vietnã, preocupação com o crescimento da população, dita, da terceira idade. Na oportunidade, definiu-se que o período de 1975 a 2025 seria a Era do Envelhecimento, onde ocorreria o crescimento mais significativo da população idosa. Nesta Assembleia ficou estabelecido que seria considerado idos o indivíduo com "65 anos nos países desenvolvidos e nos demais a partir de 60 anos em função do envelhecimento mais precoce de suas populações" (Corrêa, 1996, p. 13).

Assim, nitidamente sob a influência do entendimento da ONU, para a OMS idoso é todo indivíduo com 60 anos ou mais, dependendo do nível socioeconômico do país em que reside, considerando que em países desenvolvidos a idade pode ser delimitada a partir dos 65 anos (WHO, 2002). No Brasil, é considerado idoso a pessoa com 60 anos de idade ou mais, conforme determina a Lei 10.741 de 01/10/2003 (2003), que regulamenta o Estatuto do Idoso. Há, porém, o Projeto de Lei no 5.383/2019 (2019), tramitando na Câmara de Deputados, de autoria do Deputado Federal João Campos (GO), propondo a alteração do requisito da idade do idoso para mudar de 60 para 65 anos de idade.

Segundo dados do IBGE (2018) projetados para 2021 o Brasil tem mais de 30 milhões de pessoas nessa faixa etária, número que representa 14,69\% da população do país em 2021. No Rio Grande do Sul (RS), por exemplo, a projeção para 2021 é de mais de 2 milhões de pessoas com 60 anos ou mais, o que representa 19,35\% da população do estado. E esse percentual tende a dobrar nas próximas décadas, segundo a Projeção da População, divulgada em 2018 pelo IBGE e atualizada em 09/12/2020.

Segundo a mais recente pesquisa acerca do acesso a tecnologias da informação e comunicação, a TIC Domicílios 2019², divulgada em 26.05.2020 (NIC.br, 2019), realizada pelo Centro Regional para o Desenvolvimento de Estudos sobre a Sociedade da Informação - Cetic.br, vinculado ao Comitê Gestor da Internet no Brasil, 74\% dos brasileiros têm acesso à

\footnotetext{
${ }^{2}$ Tecnologias de informação e de comunicação.
} 
internet o que corresponde a 134 milhões de usuários, aproximadamente. Outra informação importante é que 58\% dos idosos acessam a internet via smartphones e $9 \%$ via computador. E mais, $65 \%$ dos idosos brasileiros se dizem dependentes do celular, ou seja, considerando o número de idosos prospectado para 2021, temos mais de 19 milhões de idosos reféns da tecnologia disponível em celulares e, consequentemente, na internet.

Com grande parte da família ainda economicamente ativa e no intuito de se mostrarem independentes, muitos idosos fazem a gestão de suas finanças, compras, contratos e empréstimos. Contudo, por mais ativa que uma pessoa idosa seja, é muito difícil acompanhar os avanços tecnológicos de nossa sociedade com cartões e contas digitais, compras on-line, prova de vida com reconhecimento facial, dentre outras modernidades. Infelizmente, junto com os referidos avanços, em sua maioria benéficos, surgem novas facetas criminosas, com procedimentos cada vez mais realistas forjando confiabilidade para as vítimas.

[...] o advento da tecnologia reduziu as barreiras tradicionais e, em verdade, serviu como um convite informal a visitantes desconhecidos. Muitos perceberam tarde demais os perigos de sua desatenção e se tornaram vítimas de furto, da perda de dados privados e similares. Outros permanecem ignorantes de sua vulnerabilidade, prestes a sofrerem as consequências negativas de sua postura (Britz, 2009, p. 4) .

O conceito de vulnerabilidade envolve uma série de combinações: elementos físicos, sociais e psicológicos, assim como experiências do passado e de que forma a pessoa lida com as dificuldades da vida, visto que os problemas enfrentados influenciam na qualidade de vida e na percepção de saúde (Ayres et al., 2012).

De acordo com Barbosa e colaboradores (2019), a vulnerabilidade da pessoa idosa é proveniente de diferentes condições correlacionadas entre si, tais como envelhecimento biológico, degradação da saúde, serviços de saúde precários e atendimentos inábeis, frequentes internações, redes de apoio inadequadas.

Embora o envelhecimento possa ser entendido como um processo não patológico, a própria condição traz consigo uma diminuição progressiva da funcionalidade biológica, que em determinadas condições pode favorecer quadros patológicos crônicos e aumentar a vulnerabilidade do indivíduo, como sobrecarga e estresse emocional, doenças cardiovasculares, déficits cognitivos, episódios frequentes de quedas, diminuição dos sentidos (Berardinelli et al., 2011). O avanço da idade traz consigo a falta de atenção e concentração, em razão de inúmeras alterações no sistema nervoso central, que afetam diretamente a memória, havendo redução do volume do órgão cérebro, tamanho e número de neurônios (Cançado, 1994, p.69-73).

Para Paranhos et al. (2017), a definição do termo vulnerabilidade pode ter diversas implicações. Por um lado, diz respeito a contextualização biológica, ou seja, os aspectos particulares da pessoa; mas também pode fazer alusão às condições socioeconômicas. Uma visão mais ampla de vulnerabilidade inclui aspectos ambientais, culturais e econômicos do indivíduo. Apesar da complexidade do termo, a interpretação básica de vulnerabilidade está relacionada as particularidades de cada situação, ou seja, ao sujeito e a sua condição de vida.

Partindo da concepção de que vulnerabilidade é uma condição humana universal e que diz respeito a fragilidade intrínseca do ser humano, fazendo com as pessoas passem por situações transitórias e/ou específicas, cabe mencionar a vulnerabilidade frente aos avanços tecnológicos para com a população idosa. De acordo com Araújo e Lima (2021), idosos são considerados alvos fáceis de crimes cibernéticos devido a não terem muito conhecimento da web e não conseguirem distinguir a fraude de algo legítimo.

\footnotetext{
${ }^{3}$ Livre tradução. No original: However, the advent of technology has lowered traditional barriers and actually served as an informal invitation for unknown visitors. Many have recognized only too late the dangers of their inattentiveness - victims of theft, stolen privacy, and the like; while others, yet to suffer negative consequences, remain blissfully unaware of their own vulnerability.
} 
Modernamente defende-se que em relação a determinados grupos específicos da sociedade, sobressai a chamada vulnerabilidade agravada, ou, conforme designado por Schmitt (2014, p.217), hipervulnerabilidade, impondo-se, em relação a estes últimos, uma proteção substancial. A hipervulnerabilidade pode ser definida como uma situação social fática e objetiva de agravamento da vulnerabilidade da pessoa física consumidora, em razão de características pessoais aparentes ou conhecidas pelo fornecedor (Schmitt, 2014, p.233).

Nessa classificação se enquadram as pessoas idosas, cujo risco de lesão financeira e patrimonial se potencializa frente ao crescimento do comércio eletrônico e relacionamentos virtuais, sendo quase que impossível acompanhar os avanços de forma segura, especialmente devido à natural vulnerabilidade dos indivíduos da terceira idade.

O Brasil é um dos países que mais sofre com cibercrime. No caso da população idosa, o cibercrime mais conhecido são os empréstimos consignados, seguido por recebimento de aposentadorias por terceiros e acesso a contas bancárias com o objetivo de obter ganhos no campo patrimonial. Além de perdas financeiras, existem danos em termos de convivência e abandono afetivo, pois se um terceiro possui senhas de aplicativos e redes sociais do idoso pode bloquear amigos e parentes, isolando o idoso da convivência (Fidalgo, 2019).

Em recente pesquisa realizada pela Federação Brasileira de Bancos - FEBRABAN foi identificado um substancial crescimento nas tentativas de fraudes financeiras via internet contra os brasileiros em meio à crise do Coronavírus, sendo que em relação às vítimas houve um aumento de $60 \%$ em tentativas de golpes financeiros contra idosos (2020). O isolamento social impulsionou o uso de canais digitais para atividades cotidianas, atraindo a atenção de cibercriminosos, que aproveitam o maior tempo online das pessoas para aplicar golpes, que consistem em manipulação psicológica, a fim de que o idoso forneça informações confidenciais.

O avanço da idade gera declínios cognitivos, motores e físicos. Esses fatores aliados a outras barreiras que dificultam a inclusão digital dos idosos, como baixa escolaridade, falta de locais para acesso a computadores e internet, falta de projetos e programas sociais de inclusão digital, senescência e memória de curto prazo, diminuição da atenção e concentração, audição, motricidade, visão, entre outros, torna os idosos mais susceptíveis a serem vítimas de violência por meio de tecnologia (Azevedo, 2017).

Idosos, assim como crianças, necessitam de atenção dobrada em relação a segurança na internet. Enquanto as novas gerações nasceram e cresceram na era da informação, os internautas idosos não estão familiarizados com golpes online e por isso precisam de orientação e acompanhamento. Uma vez que mais idosos estão usando as ferramentas tecnológicas, mais comum é a confusão ao lidar com este universo. É importante serem orientados a não se exporem em redes sociais, como compartilhar a localização em imagens ou transmitir fake news em aplicativos de conversa, visto que estará sujeito a consequências jurídicas (2018).

Um dos golpes mais comuns aplicados a idosos é o chamado phishing, que são e-mails ou sites falsos que roubam a identidade e os dados do usuário. O perigo para idosos são principalmente as mensagens de texto que chegam no celular (SMS), pegando-os desprevenidos e fazendo-os clicar em links falsos. Uma forma de minimizar o phishing é avisar ao idoso que os bancos não enviam este tipo de mensagem e instalar dispositivos de segurança, como antivírus nos equipamentos (2018).

Os ataques e golpes da internet não são direcionados apenas a idosos, podendo qualquer pessoa ser vítima. No entanto, a população idosa tem menos conhecimento e está um pouco mais despreparada que a maioria; acreditam com mais facilidade nas informações e são mais fáceis de ludibriar. Além do phishing em e-mail e rede social na forma de anúncios, tem também a clonagem do whatsapp. É preciso ficar atento, principalmente se pedir dinheiro ou algum dado pessoal. A melhor maneira de evitar cair em golpes é prestar atenção (Sampaio, 2020). 


\subsection{Proteção financeira de idosos}

De acordo com o Estatuto do Idoso ou Lei $n^{\circ}$ 10.741/2003, em seu artigo 102, é crime "se apropriar ou desviar benefícios, bens, proventos, pensão ou qualquer outro dinheiro/rendimento do idoso, a fim de dar-lhe aplicação diferente da finalidade, com pena de 1 a 4 anos e multa". Este tipo de crime ocorre quando o idoso precisa de ajuda e confia na pessoa que deveria auxiliá-lo: familiar, pessoa próxima, funcionário do banco ou de instituição, que se aproveita do acesso facilitado ao patrimônio do idoso (2003).

Embora os idosos tenham independência para atividades básicas, as alterações do processo de envelhecimento geram a necessidade de adaptação da forma de viver em alguns aspectos. $\mathrm{O}$ fato de o idoso adoecer ou algum outro motivo em que perca sua autonomia, familiares ou vizinhos podem se apropriar dos bens, pois o idoso confia, passando administrar as finanças (Confortin et al., 2017).

Considerando esta condição da pessoa idosa, que fica a mercê de doenças e redução da capacidade funcional ou cognitiva, algumas medidas de proteção precisam ser tomadas, como a lei nº 12.461/2011 (2011), que tornou obrigatória a notificação de casos de violência contra o idoso, independente do tipo, a fim de atender as necessidades e melhorar a qualidade de vida da população da terceira idade (Alarcon et al., 2019).

A melhor forma de proteção é a sensibilização da sociedade em geral, para que possa reconhecer as situações de abuso contra os idosos e direcionar a vítima, entendendo que se trata de uma situação complexa que envolve comunidade, família e órgãos governamentais. Cabe ao indivíduo que observa, identificar as características do contexto da agressão, para prevenir novas ocorrências (Silva et al., 2016).

Para fins de proteção, quando se trata da população idosa, o documento que impera é o Estatuto do Idoso ou a Lei Federal $n^{\circ}$ 10.741/2003 (2003), que foi organizado para regular os interesses e garantias das pessoas idosas e está vigente desde o ano de 2004, servindo como um importante instrumento de cidadania e proteção às pessoas com idade igual ou superior a 60 anos, no que diz respeito ao direito à vida, liberdade, dignidade, saúde, respeito, educação, segurança, esporte, lazer, previdência e assistência social, transporte, habitação etc (Pretel e Pretel, 2010).

Proteger a dignidade da pessoa idosa e cuidar para que nenhuma negligência seja sofrida é dever de todos, conforme afirma o artigo $3^{\circ}$ do Estatuto do Idoso:

É obrigação da família, da comunidade, da sociedade e do Poder Público, efetivar o direito à vida, à saúde, à alimentação, à educação, à cultura, ao esporte, ao lazer, ao trabalho, à cidadania, à liberdade, à dignidade, ao respeito e à convivência familiar.

$\S 2^{\circ}$ Dentre os idosos, é assegurada prioridade especial aos maiores de oitenta anos, atendendo-se suas necessidades sempre, preferencialmente em relação aos demais idosos (Lei n ${ }^{\circ}$ 13.466/2017).

Esses cuidados e proteção também envolvem a vida financeira dos idosos. Visando manter a proteção da pessoa idosa, saques e transações bancárias no lugar do idoso realizadas por um terceiro, demandam uma procuração por instrumento público, apesar de não existir uma obrigatoriedade, ou seja, um documento feito em cartório. Dessa forma, é interessante que o idoso que está impossibilitado faça uma procuração detalhada sobre as ações que o terceiro poderá executar por ele (Brugnolo, 2020).

Para evitar conflitos, ao cuidar das finanças dos idosos, é preciso que haja diálogo e que alguns pontos sejam esclarecidos, agindo com cautela e empatia a fim de poupar desgastes desnecessários. A situação de cuidado deve sempre ser compartilhado com toda a família, ou seja, não se deve tomar conta e assumir a vida do idoso, mas sim oferecer ajuda no dia a dia com pagamento de contas, compras e outras tarefas que envolvam as finanças (Zorub, 2018). 
Dando continuidade, o autor complementa que agir da forma menos invasiva possível proporciona confiança ao idoso, resgate da autoestima e maior qualidade de vida. Além disso, uma conversa sincera é importante, a fim de abordar o assunto de forma tranquila e sem neutralizar as suas habilidades. A transição do cuidado das finanças precisa ser feita lentamente e de maneira clara, dando ao idoso autonomia para lidar com o próprio dinheiro (Zorub, 2018).

A segurança financeira do idoso envolve manter a qualidade de vida. Desta forma, não se deve proibir a pessoa de continuar sua rotina de controle, nem interferir de forma brusca nos hábitos rotineiros. Entre as ações a serem tomadas, pode-se considerar: colocar as contas em débito automático; montar um calendário para o restante das contas, que deve estar disponível para o idoso e o cuidador; o cuidador só deve executar o pagamento, caso o idoso não consiga fazer; fazer as compras juntamente com o idoso; investigar empréstimos e gastos excessivos no orçamento, assim como valores que comprometam a renda (Martinelli, 2018).

Por fim, ressalta-se que importante Lei foi recentemente sancionada a qual amplia o combate à prática de fraudes eletrônicas, alterando o Código Penal e Código de Processo Penal, trata-se da Lei Ordinária 14.155/2021, de 27 de maio de 2021. Dentre alguns objetivos, a lei tipificou o crime de furto qualificado pela fraude com o uso de dispositivo eletrônico ou de dados eletrônicos fornecidos indevidamente, com aumento de pena nos casos de vítima idosa.

\section{Metodologia}

A pesquisa é um estudo descritivo, de abordagem qualitativa, realizado por meio de análise documental e bibliográfica, a partir da legislação nacional vigente e de estudos realizados acerca do tema, buscando identificar como a pessoa idosa está amparada legalmente no que diz respeito a proteção financeira.

Quanto a pesquisa bibliográfica, ela é importante por ser um passo inicial na construção do estudo, a fim de conhecer as publicações acerca do tema. Esta metodologia de pesquisa coloca o pesquisador em contato direto com toda a produção científica sobre a temática estudada, sendo primordial a verificação dos dados obtidos e a observação de contradições e incoerências que os textos possam trazer (Prodanov et al., 2013).

Quanto a análise documental, Cellard (2008) afirma que ela precisa ser apreciada e valorizada. A riqueza de informações que o uso de documentos pode trazer justifica seu uso em várias áreas, pois amplia o entendimento do objeto de pesquisa, cuja compreensão envolve a contextualização histórica e sociocultural. Além disso, o uso de documentos favorece o processo de evolução do objeto de estudo, conhecimentos, práticas, comportamentos, entre outros.

A temática central da pesquisa foi a proteção de idosos em relação a violência financeira no âmbito da Lei Geral de Proteção de Dados, usando a legislação nas esferas estadual e federal a fim de contextualizar o direito debatido.

A pesquisa foi realizada entre os meses de janeiro a junho de 2021, buscando artigos, estudos e documentos que tratassem da temática citada. Inicialmente foi realizada busca no Google Scholar (www.scholar.google.com) utilizando os termos "Violência Financeira contra o idoso"; "Proteção da Terceira Idade"; "Finanças e Idosos"; "Proteção de dados e idosos", a fim de buscar trabalhos semelhantes a esta pesquisa.

A coleta de dados envolveu, ainda, algumas etapas: definição das bases de dados para busca de artigos, limitação do espaço de tempo; idioma; descritores; critérios de inclusão e exclusão. Em relação a busca de documentos, foi feito um levantamento das principais políticas voltadas para a proteção de dados do idoso, baseando-se na recente lei denominada LGPD. Utilizou-se o espaço de tempo 2010 a 2020, buscando contextualizar os últimos dez anos do histórico legislativo no Brasil e de estudos publicados sobre o tema.

O estudo foi realizado por meio de análise de conteúdo, na modalidade temática, seguindo algumas etapas, conforme proposto por Alarcon et al. (2019): a) pré-análise: organização do material coletado, realizando-se a leitura exaustiva dos artigos e documentos, que constituem o corpus de análise; nesta etapa houve a preparação de todo material que foi usado na 
sequência; b) exploração do material: recortes dos registros encontrados, classificação das informações; c) tratamento e interpretação dos resultados: realização da síntese interpretativa a fim de atingir os objetivos da pesquisa, atrelando os artigos científicos e as informações documentais.

Dando sequência, os resultados serão apresentados.

\section{Resultados e Discussão}

Percebe-se que, a partir da revisão bibliográfica, com a revolução tecnológica a sociedade passou a estar permanentemente em rede, mantendo as pessoas intelectual, emocional e socialmente ativas. Ledo engano, contudo, imaginar que o ciberespaço está dominado apenas por internautas jovens. As inovações tecnológicas, especialmente as vinculadas à internet, são úteis, acessíveis e, até, saudáveis para pessoas idosas.

Conforme evidenciado na pesquisa, o IBGE (2018) projetou que em 2021 o Brasil contaria com mais de 30 milhões de pessoas idosas (com 60 anos ou mais), representando 14,69\% da população do país. Verifica-se, ainda, que, segundo a pesquisa TIC Domicílios 2019, 58\% dos idosos acessam a internet via smartphones e 9\% via computador, sendo que $65 \%$ dos idosos brasileiros se declaram dependentes do celular, ou seja, mais de 19 milhões de idosos.

A crescente difusão da internet, a popularização das redes sociais e os reduzidos valores comerciais de aparelhos eletrônicos contribuíram para a inclusão digital dos idosos. Contudo, somado a isto temos um grande aumento de computadores pessoais nos últimos anos, ou seja, qualquer pessoa pode realizar golpes virtuais, como roubo de dados, de qualquer lugar do mundo. Neste sentido, o público idoso, por inocência e falta de conhecimento, acaba se tornando presa fácil para os cibercriminosos.

Desde final de 2019 estamos vivendo um período, já bastante longo, de pandemia causada pelo novo Coronavírus, sendo uma das estratégias de prevenção o isolamento social. Uma das principais faixas etárias em isolamento, por ser naturalmente um grupo de risco, é a dos idosos. E neste momento em que a maioria da sociedade está buscando a proteção dos idosos, associações criminosas atualizam e intensificam golpes financeiros se aproveitando do aumento de tempo online dos cidadãos e das transações digitais devido à quarentena.

Como evidenciado na pesquisa bibliográfica, via de regra, a predileção dos bandidos para a aplicação de muitos golpes virtuais é a população idosa, pois esta possui uma crescente diminuição no raciocínio em razão da falta de atenção e concentração que, como demonstrado na revisão, ocorrem por degeneração fisiológica natural, além de possuírem uma menor inserção digital.

São infindáveis as modalidades de golpes eletrônicos: phishing via e-mail ou celular; falso motoboy do banco; leilão falso; clonagem da conta de whatsapp; cartão de crédito extraviado; cobrança a maior em compra delivery. Mas o que a maioria dessas fraudes têm em comum é o conhecimento prévio de alguns dados pessoais das vítimas, como celular, nome completo, CPF e até número da conta bancária. Esses dados, muitas vezes, são furtados via mensagens maliciosas de e-mail, whatsapp, links falsos de sites. Outras vezes esses dados pessoais são fornecidos pelo próprio titular ao realizar cadastros em sites sob a promessa de participar de sorteios, obter ofertas ou serviços gratuitos. Percebe-se, assim, a hipervulnerabilidade da Terceira Idade frente as inúmeras ferramentas e riscos da sociedade de rede.

De posse dos dados pessoais alheios, criminosos realizam compras online, invadem contas de whatsapp ou até conta bancária, fazem saques, transferências, pix. São infindáveis as possibilidades de estelionato tendo em mãos dados básicos de qualquer indivíduo.

As instituições financeiras se defendem afirmando que os sistemas ofertados para transações bancárias são seguros, realizados em ambiente autenticado e criptografado. Mas nada disso põe o usuário, principalmente o idoso, a salvo de 
tentativas de fraudes via engenharia social, especialmente num momento de pandemia, de isolamento social e vulnerabilidade emocional, tornando-o um alvo fácil para a argúcia criminosa e violência financeira.

A recém-nascida LGPD com certeza não irá salvar a sociedade do furto e manipulação dos dados pessoais mas, inevitavelmente, trouxe ao debate a importância de ferramentas que auxiliem na sua proteção, localizem e responsabilizem os autores pelo uso indevido desses dados. A referida legislação trouxe uma série de necessidades para proteção de dados, sendo que o vazamento, furto ou extravio pode ensejar multas ou outras proibições civis e administrativas.

De qualquer forma, a LGPD surgiu com o fito de certificar a proteção aos direitos fundamentais que encontram base na CF/88 (1988), como o direito à privacidade, intimidade, honra e dignidade. Os crescentes avanços tecnológicos não podem ser freados, mas suas ameaças precisam ser fortemente, se não afastadas, pedagogicamente repreendidas. Neste sentido, a LGPD se mostra fundamental, não só para proteger e responsabilizar àqueles que forem negligentes no tratamento de dados, mas também para garantir o acesso à informação e ao consentimento do titular.

As compras realizadas por meio da internet demandam que o consumidor compartilhe uma grande quantidade de dados pessoais. Para as empresas de e-commerce esses dados passam a ser preciosos ativos no mundo dos negócios, possivelmente o commodity ${ }^{4}$ mais desejado na sociedade digital. Quanto maior o volume de dados controlados por uma pessoa ou empresa, maior seu poder comercial e econômico. Assim, impõem-se a adoção de medidas pelas empresas no campo da cibersegurança, a fim de prevenir o vazamento dessas informações e consequente responsabilização por danos causados aos titulares dos dados.

Após análise da LGPD, verificamos que, segundo o art. 55-J, inciso IV, incluído pela Lei no 13.853 , de 08 de julho de 2019 (2019), compete à Autoridade Nacional de Proteção de Dados (ANPD) a incumbência de fiscalizar e aplicar as sanções. Ainda, especificamente em relação ao idoso, segundo o inciso XIX do referido artigo:

\section{Art. 55-J. Compete à ANPD:}

XIX. Garantir que o tratamento de dados de idosos seja efetuado de maneira simples, clara, acessível e adequada ao seu entendimento, nos termos da LGPD e da Lei $\mathrm{n}^{\circ} 10.741$, de $1^{\circ}$ de outubro de 2003 (Estatuto do Idoso);

É possível perceber que a LGPD, neste ponto, está harmonizada com o Estatuto do Idoso, Lei 10.741/2003 (2003), apresentando uma proteção substancial em razão das limitações da idade. Deve-se atentar, ainda, para o fato de que o próprio Estatuto do Idoso prevê como crime a conduta de receber ou desviar bens, dinheiro ou benefícios de idosos:

Estatuto do Idoso - Lei No 10.741, DE $1^{\circ}$ de outubro de 2003.

$[\ldots]$

Art. 102. Apropriar-se de ou desviar bens, proventos, pensão ou qualquer outro rendimento do idoso, dando-lhes aplicação diversa da de sua finalidade:

Pena - reclusão de 1 (um) a 4 (quatro) anos e multa.

Esse tipo de crime pode ocorrer com a utilização dos artifícios que o cyber espaço possibilita, mediante furto de dados pessoais e engenharia social persuasiva, sendo as etapas iniciais para uma violência financeira ainda mais prejudicial.

Verificou-se que a LGPD regulamenta a questão da coleta, tratamento e armazenamento dos dados, com sanções administrativas para os casos de vazamento destes dados ou utilização indevida. Contudo, a legislação se dirige à relação das empresas com a pessoa física, titular dos dados pessoais. Ou seja, se aplica à coleta de dados legal, legítima, autorizada de forma consciente.

\footnotetext{
${ }^{4}$ Expressão do inglês que significa bem ou produto de origem primária comercializado junto às bolsas de mercadorias e valores.
} 
Mantendo o objetivo da presente pesquisa, foi possível determinar o grau de proteção da LGPD em relação aos idosos. A finalidade da coleta dos dados deve ser muito bem esclarecida para todos os indivíduos titulares dos dados, porém, em se tratando de idosos, as informações devem ser repassadas de forma a garantir o pleno entendimento da finalidade, utilização, armazenamento, formas de acessar as informações, tempo de armazenamento e, até, consequências em caso de vazamento destes dados. Caso contrário, a coleta e tratamento se dará de forma ilegítima, com consentimento viciado.

A legislação aprofundada na presente pesquisa estabelece, então, princípios para as condutas de segurança da informação com responsabilização administrativa, atuando na prevenção de fraudes. Ou seja, caso a coleta dos dados se dê de forma fraudulenta via empresas de fachada ou cibercriminosos, causando prejuízos financeiros aos idosos, público preferido neste esquema ardiloso, a LGPD pouco auxiliará na punição e restituição do dano.

\section{Conclusão}

Constatou-se, na presente pesquisa, que a sociedade moderna possui um grande percentual de idosos. Segundo dados do IBGE projetados para 2021, o Brasil tem mais de 30 milhões de pessoas com 60 anos ou mais, o que representa 14,69\% da população do país. Ainda, em pesquisa acerca do acesso a tecnologias da informação e comunicação no Brasil, a TIC Domicílios $2019^{5}$, verificou-se que $58 \%$ dos idosos acessam a internet via smartphones e $9 \%$ via computador, sendo que $65 \%$ dos idosos se definem como dependentes do celular, ou seja, mais de 19 milhões de idosos são reféns da tecnologia disponível em celulares e, consequentemente, na internet.

Nunca o uso de tecnologia da informação foi tão útil e necessário para a movimentação e evolução da sociedade, especialmente agora em meio à pandemia. Porém, a população idosa não foi devidamente preparada para este uso massivo de tecnologia e, ademais, possui limitações cognitivas causadas pelo avanço da idade que a torna um alvo vulnerável nas mãos de criminosos astutos. Destaca-se que não é salutar tornar um idoso dependente de um terceiro para transações que exijam tecnologia, mas sim treiná-lo, ensinando a utilizar as ferramentas de proteção de seus dados de forma correta, primando pela segurança financeira e emocional.

Apurou-se, de forma irrefutável, que a edição da LGPD demonstra que o Brasil está buscando disponibilizar ferramentas legais que protejam os dados pessoais dos cidadãos, a exemplo de inúmeros países da comunidade internacional. A referida lei trouxe diversos avanços na proteção dos dados das pessoas físicas, regulando e condicionando a coleta, tratamento e armazenagem desses dados. A referida legislação, inspirada na regulamentação europeia, buscou a defesa dos dados pessoais considerando que não existem mais dados irrelevantes diante do processamento eletrônico e universal de dados na sociedade da informação, cabendo ao titular dos dados dispôr deles de acordo com seus interesses. Almeja-se que a lei em análise seja bem aplicada, solidificando a confiança e segurança jurídica entre os envolvidos no processo de tratamento de dados, protegendo a privacidade dos indivíduos sem inviabilizar a inovação tecnológica.

Demonstrou-se, ainda, que embora a LGPD deva ser considerada como um marco regulatório na proteção dos dados pessoais, as formas de combate aos crimes cibernéticos continuam débeis, sendo que somente em legislações apartadas existe a tipificação de alguns crimes desta natureza, como é o caso da recente Lei 14.155/2021, já referida nesta pesquisa. Ressalta-se que, segundo essa lei, o estelionato praticado por meio eletrônico contra idosos ou vulneráveis deverá ter a pena aumentada de $1 / 3$ ao dobro.

Entende-se que a legislação (LGPD) estudada se dirige à relação das empresas com a pessoa física, titular dos dados pessoais, sendo norteadora de todas as tramitações destes dados, estabelecendo sanções civis e administrativas. Como já

\footnotetext{
5 Tecnologias de informação e de comunicação.
} 
considerado, caso a coleta dos dados se dê de forma fraudulenta, causando prejuízos financeiros, em especial, aos idosos, a LGPD pouco auxiliará na punição e restituição da lesão.

Ademais, aspira-se que a LGPD seja cumprida em sua integralidade, tornando efetivas as garantias constitucionais da privacidade, intimidade, sigilo de dados e dignidade, em diálogo com as demais leis brasileiras que dispõem sobre a proteção de dados, sobretudo com a recente Lei 14.155/2021.

Por fim, como sinalado no início desta breve exposição, o presente trabalho não busca esgotar o tema, mas justamente o oposto. Busca-se, sim, fomentar o debate quanto ao zelo dos dados pessoais dos idosos, o que implica, em última análise, na proteção deste contra a violência financeira. Ainda, o atual contexto em que se encontra a sociedade, em meio a uma pandemia e necessária informatização da vida, faz com que se imponha uma intensificação nas discussões sobre o assunto, apresentando soluções para, de fato, efetivar os direitos e garantias já abarcados nas legislações vigentes.

O presente estudo é apenas uma abordagem inicial da proteção diferenciada que a legislação pode trazer em favor, especificamente, dos idosos. É preciso que se atente ao fato de que novas leis ou alterações na atual LGPD e leis esparsas devem considerar a hipervulnerabilidade da população idosa, que cresce em proporções geométricas em nosso país. Meras leis principiológicas não garantem a inviolabilidade dos direitos da Terceira Idade, como intimidade, privacidade e dignidade.

Acredita-se que a criação da Autoridade Nacional que regula, fiscaliza, apura ilícitos e aplica sanções na esfera privada e pública, foi um importante passo, mostrando que os aplicadores do Direito estão cientes de que a LGPD restou debilitada de efetividade. Absurdamente a criação desta autoridade foi vetada, mas a falha foi contornada com a edição da Lei $13.853 / 2019$.

$\mathrm{Na}$ verdade, acredita-se que as leis esparsas que tipificam os crimes cibernéticos têm o poder de proteger de forma mais efetiva os dados de todo cidadão, em especial, dos idosos, uma vez que apresenta sanções penais para a conduta criminosa.

A tímida regulamentação e proteção trazida pela LGPD não tem o condão de diminuir sua importância como marco regulatório, uma vez que, se adequadamente aplicada, tem o poder de conferir novas condutas nas organizações públicas e privadas, garantindo a proteção dos dados pessoais dos indivíduos. Espera-se que a legislação brasileira siga evoluindo e ampliando a proteção dos dados pessoais da sociedade, visto que a LGPD é apenas um engatinhar; uma carta de intenções; um aviso do que ainda está por vir.

Outrossim, urge o enfrentamento de inúmeros aspectos da LGPD que só estão sendo percebidos agora, a partir de sua entrada em vigor, como seu caráter extraterritorial, uma vez que abrange dados tratados fora do Brasil; a questão da eliminação dos dados pessoais tratados de forma irregular, bem como a aplicação da pré citada lei em relações trabalhistas, com tratamento das informações do empregado e demais trabalhadores.

\section{Agradecimentos}

Este trabalho foi apoiado por subsídios da Associação de estudo, pesquisa e auxílio às pessoas com Alzheimer (AEPAPA), a qual devota-se toda gratidão.

\section{Referências}

Alarcon, M. F. S., Paes, V. P., Damaceno, D. G., Sponchiado, V. B. Y. \& Marin, M. J. S. (2019). Violência financeira: circunstâncias da ocorrência contra os idosos. Revista Brasileira de Geriatria e Gerontologia, 22(6).

Araújo, G., \& Lima, G. (2021). Idoso é alvo fácil de invasores na internet. O Estadão. 2021. https://infograficos.estadao.com.br/focas/planeje-sua-vida/idosoe-alvo-facil-de-invasores-na-internet.

Assis, C. \& Mendes, L. (2021). Histórico das leis de proteção de dados e da privacidade na internet. https://assisemendes.com.br/historico-protecao-de-dados. 
Ayres, J. R. C. M., Calazans, G. J., Saletti, H. C. J. \& França, I. J. (2009). Risco, vulnerabilidade e práticas de prevenção e promoção da saúde. In: Akerman, M., Campos, G.W.S., Carvalho, Y.M., Drumond, M.J., Minayo, M.C.S.H. (2009). Tratado de Saúde Coletiva. (2a ed.), Fiocruz, 375-418.

Azevedo, C. (2017). TIC e sociedades cada vez mais envelhecidas: uma contextualização de estudos no Brasil, em Portugal e em outros países. Verso e Reverso, 31(76),14-25.

Barbosa, K. T. F., Oliveira, F. M. R. L. \& Fernandes, M. G. M. (2019). Vulnerabilidade da pessoa idosa: análise conceitual. Revista Brasileira de Enfermagem, 72(2).

Berardinelli, L. M. M., Santos, I., Santos, M. L. C. S., Lima, T. C. L. \& Missio, A. C. (2011). Identificando vulnerabilidade para complicações cardiovasculares em idosos: uma estratégia para o cuidado. Revista de Enfermagem UERJ, 19(4), 541-6.

Bioni, B. R. (2020). Proteção de Dados Pessoais: a função e os limites do consentimento. (2a ed.), Forense.

Britz, Marjie T. (2009). Computer forensics and cybercrime: An introduction. Prentice Hall.

Brugnolo, B. (2020). Como proteger idosos da violência patrimonial durante a pandemia. Gazeta do povo. https://www.gazetadopovo.com.br/vida-ecidadania/como-proteger-idosos-da-violencia-patrimonial-durante-a-pandemia.

Cançado, Flávio Aluizio Xavier. (1994). Noções práticas de geriatria. Coopmed.

Cellard, A. (2008). A análise documental. In: Poupart, J. A pesquisa qualitativa: enfoques epistemológicos e metodológicos. Vozes.

Confortin, S. C., Schneider, I. J. C., Antes, D. L., Cembranel, F., Ono, L. M. \& Marques, L. P. (2017). Condições de vida e saúde de idosos: resultados do estudo de coorte EpiFloripa Idoso. Epidemiologia e Serviços de Saúde, 26(2), 305-17.

Conheça as tentativas de golpes financeiros mais comuns na pandemia e saiba como evitá-los. (2020). Federação Brasileira de Bancos. https://portal.febraban.org.br/noticia/3522/pt-br.

Constituição da República Federativa do Brasil, de 05 de outubro de 1988. http://www.planalto.gov.br/ccivil_03/constituicao/constituicao.htm.

Corrêa, Antonio C. de O. (1996). Envelhecimento, depressão e doença de Alzheimer. Health.

Crianças e idosos na internet exigem cuidados especiais. (2018). O GLOBO. https://nic.br/noticia/na-midia/criancas-e-idosos-na-internet-exigem-cuidadosespeciais-dizem-especialistas.

Envelhecimento ativo: um projeto de política de saúde. (2005). Organização Mundial de Saúde (OMS), Brasília: Organização Pan-Americana.

Fidalgo, A. (2019). Idosos e a vulnerabilidade digital. https://administradores.com.br/artigos/idosos-e-a-vulnerabilidade-digital.

Gomes, H. S. (2019). Lei Geral de Proteção de Dados (LGPD): uma análise dos impactos da lei na cultura e tratamento de dados no Brasil. 28f. Trabalho de Conclusão de Curso (Graduação em Tecnologia em Análise e Desenvolvimento de sistemas), Universidade do Sul de Santa Catarina, UNISUL, Florianópolis, SC.

Guia Financeiro e Patrimonial para pessoas idosas: orientação e proteção 60+. (2020). Governo do Estado. Secretaria de Justiça, Família e Trabalho. Curitiba, PR. https://www.justica.pr.gov.br/sites/default/arquivos_restritos/files/documento/2020-10/Guia\%20Financeiro\%20Terceira\%20Idade_new.pdf..

Guimarães, D. B. O., Mendes, P. N., Rodrigues, I. S., Feitosa, C. D. A., Sales, J. C. S. \& Figueiredo, M. L. F. (2016). Caracterização da pessoa idosa vítima de violência. Revista de Enfermagem da UFPE, 10(3), 1343-50.

Irigaray, T. Q., Esteves, C. S., Pacheco, J. T. B., Grassi-Oliveira, R. \& Argimon, I. I. L. (2016). Maus-tratos contra idosos em Porto Alegre, Rio Grande do Sul: um estudo documental. Estudos de Psicologia, 33(3), 543-51.

Lei Federal $n^{o}$ 10.741, de 01 de outubro de 2003. Estatuto do Idoso. Brasília, DF: Secretaria Especial dos Direitos Humanos. http://www.planalto.gov.br/ccivil_03/leis/2003/110.741.htm.

Lei Federal $n^{\circ} 12.461$, de 26 de julho de 2011. Altera a Lei $\mathrm{n}^{\circ} 10.741$, de $1^{\circ}$ de outubro de 2003, para estabelecer a notificação compulsória dos atos de violência praticados contra o idoso atendido em serviço de saúde. http://www.planalto.gov.br/ccivil_03/_ato2011-2014/2011/lei/L12461.htm.

Lei $n^{\circ}$ 13.709, de 14 de agosto de 2018. Lei Geral de Proteção de dados pessoais. http://www.planalto.gov.br/ccivil_03/_Ato2015-2018/2018/Lei/L13709.htm.

Lei $n^{\circ} 13.853$, de 8 de julho de 2019. Altera a Lei n 13.709 , de 14 de agosto de 2018, para dispor sobre a proteção de dados pessoais e para criar a Autoridade Nacional de Proteção de Dados; e dá outras providências. Brasília, DF: Presidência da República. http://www.planalto.gov.br/ccivil_03/_ato20192022/2019/lei/113853.htm.

Lei $n^{\circ}$ 14.155, de 27 de maio de 2021. Altera o Decreto-Lei no 2.848, de 7 de dezembro de 1940 (Código Penal), para tornar mais graves os crimes de violação de dispositivo informático, furto e estelionato cometidos de forma eletrônica ou pela internet; e o Decreto-Lei no 3.689, de 3 de outubro de 1941 (Código de Processo Penal), para definir a competência em modalidades de estelionato. Brasília, DF: Presidência da República. http://www.planalto.gov.br/ccivil_03/_ato2019-2022/2021/lei/L14155.htm.

Leite, G. (2020). Breves esclarecimentos sobre a Lei Geral de Proteção de Dados no Brasil (LGPD). https://www.jornaljurid.com.br/colunas/giseleleite/breves-esclarecimentos-sobre-a-lei-geral-de-protecao-de-dados-do-brasil-lgpd.

Lima, F. D. M. (2014). Teoria de Betty Neuman no cuidado à pessoa idosa vítima de violência. Revista Baiana de Enfermagem, 28(3), 219-24.

Lugati, L. N. \& Almeida, J. E. (2020). Da evolução das legislações sobre Proteção de dados: a necessidade de reavaliação do papel do consentimento como garantidor da autodeterminação informativa. Revista de Direito de Viçosa, 12(2). 
Maldonado, V. N. \& Blum, R. O. (2019). LGPD: Lei Geral de Proteção de Dados comentada. Revista dos Tribunais.

Martinelli, J. (2018). Quatro dicas para auxiliar o controle das finanças no início da Doença de Alzheimer. Portal do Idoso. https://idosos.com.br/controledas-financas-de-da.

Mendes, L. S. (2014). Privacidade, proteção de dados e defesa do consumidor: linhas gerais de um novo direito fundamental. Saraiva.

Mendes, L. S. \& Doneda, D. (2018). Reflexões iniciais sobre a nova Lei Geral de Proteção dos Dados. Revista do Direito do Consumidor, 120(3), 469-83.

Moreira, W. C., Damasceno, C. K. C. S., Vieira, S. K. S. F., Campêlo, T. P. T., Campêlo, D. S. \& Alencar, D. C. (2016). Análise sobre as políticas públicas de enfrentamento a violência contra o idoso. Revista de Enfermagem UFPE, 10(4), 1324-31.

Paludetto, V. \& Barbieri, H. (2019). Guia sobre a Nova Lei Geral sobre Proteção de Dados. Ebook Kindle. https://www.amazon.com.br/kindle-

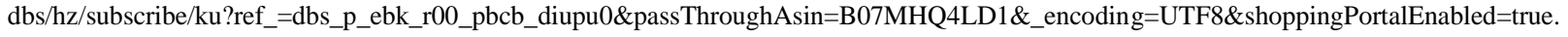

Paranhos, D. G. A. M., Albuquerque, A. \& Garrafa, V. (2017). Vulnerabilidade do paciente idoso à luz do princípio do cuidado centrado no paciente. Saúde e sociedade, 26(4).

Pecsen, Thaisy. (2021). Vazamento em massa expões número de CPF de milhões de brasileiros: Alerta PSafe. DFNDR blog. https://www.psafe.com/blog/vazamento-expoe-numero-de-cpf-de-milhoes-de-brasileiros-alerta-psafe.

Pesquisa sobre o uso das tecnologias de informação e comunicação: Pesquisa TIC Domicílios. (2019). Núcleo de Informação e Coordenação do Ponto BR NIC.br. http://cetic.br/pt/arquivos/domicilios/2019/individuos.

Pretel e Pretel, M. (2010). A proteção ao idoso e a possibilidade de retirada de um parente do lar familiar. $O A B$ SP. https://www.oabsp.org.br/subs/santoanastacio/institucional/artigos-publicados-no-jornal-noticias-paulistas/a-protecao-ao-idoso-e-a-possibilidade-de-retirada.

Prodanov, C. C. \& Freitas, E. C. (2013). Metodologia do trabalho científico: métodos e técnicas da pesquisa e do trabalho acadêmico. Feevale.

Projeções da população. (2018). Instituto Brasileiro De Geografia E Estatística. IBGE. https://www.ibge.gov.br/estatisticas/sociais/populacao/9109-projecaoda-populacao.html?=\&t=resultados.

Projeto de Lei $n^{\circ}$ 5.383, de 03 de outubro de 2019. Brasília, DF. https://www.camara.leg.br/proposicoesWeb/fichadetramitacao?idProposicao=2223942.

Reis, L. A., Gomes, N. P., Reis, L. A., Menezes, T. M. O. \& Carneiro, J.B. (2014). Expressão da violência intrafamiliar contra idosos. Acta Paulista de Enfermagem, 27(5), 434-9.

Rodotà, S. (2008). A vida na sociedade da vigilância: a privacidade hoje. Renovar.

Sampaio, C. (2020). Proteste alerta para riscos de golpes cibernéticos envolvendo idosos. Brasil de Fato. https://www.brasildefato.com.br/2020/08/29/proteste-alerta-para-riscos-de-golpes-ciberneticos-envolvendo-idosos.

Schmitt, Cristiano Heineck. (2014). Consumidores Hipervulneráveis: A proteção do idoso no mercado de consumo. Atlas.

Silva, C. F. S. \& Dias, C. M. S. B. (2016). Violência contra idosos na família: motivações, sentimentos e necessidades do agressor. Revista Psicologia: Ciência e Profissão, 36(3), 637-52.

Stelzer, J., Gonçalves, E. N., Baptista, R. R. F., Vaz, R. M. P., Wieira, K. \& Fidelis. M. M. (2019). A Lei Geral de Proteção de dados pessoais e os desafios das instituições de ensino superior para a adequação. In: Colóquio Internacional De Gestão Universitária, 19. Anais do XIX CIGU, Florianópolis, SC.

Tentativas de golpes financeiros contra idosos aumentam 60\% na pandemia. (2020). Federação Brasileira de Bancos. São Paulo, SP. https://noomis.febraban.org.br/temas/seguranca/tentativas-de-golpes-financeiros-contra-idosos-aumentam-60-na-pandemia.

Veras, Renato Peixoto \& Caldas, Célia Pereira. (2004). Promovendo a saúde e a cidadania do idoso: o movimento das universidades da terceira idade. Ciência \& Saúde Coletiva. 9(2), 423-32. https://doi.org/10.1590/S1413-81232004000200018.

Verdi, N. C. (2021). Violência financeira contra o idoso e a recomendação 46/2020 do CNJ. Portal do envelhecimento e longeviver. https://www.portaldoenvelhecimento.com.br/violencia-financeira-contra-o-idoso-e-a-recomendacao-46-2020-do-cnj.

WHO. (2002). Active Ageing: A Police Framework. A Contribution of the World Health Organization to the second United Nations World Assembly on Aging. World Health Organization (WHO). Madrid, Spain, april. https://extranet.who.int/agefriendlyworld/wp-content/uploads/2014/06/WHO-Active-AgeingFramework.pdf.

Zorub, M. V. (2018). Qual o melhor método para cuidar das finanças dos idosos? Guardiões de vidas. https://guardioesdevidas.com/04/07/2018/como-cuidardas-financas-dos-idosos-vamos-conversar-sobre-isso. 